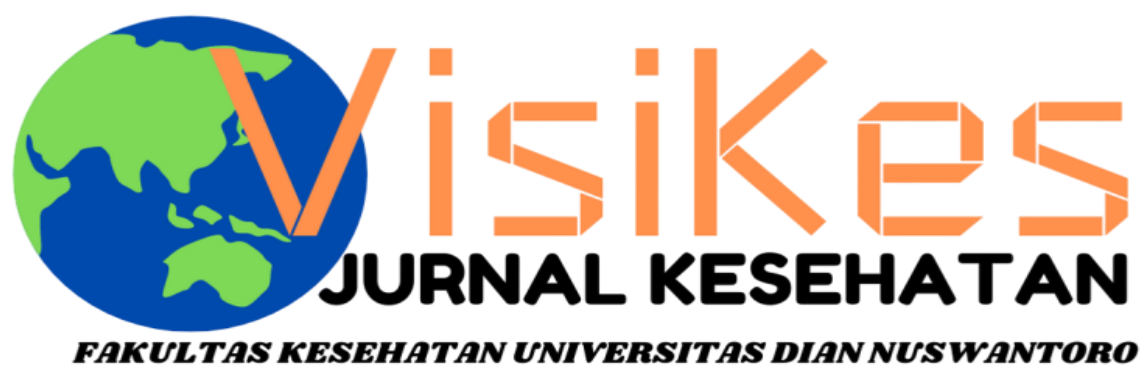

ISSN 1412-3746

FAKULTAS KESEHATAN UNIVERSITAS DIAN NUSWANTORO

Persepsi Mahasiswa Keperawatan Tentang Eskalasi Tenaga Perawat

Rendi Ariyanto Sinanto', Vivi Retno Intening ${ }^{2}$

Risiko kesehatan $\mathrm{Pb}$ dan $\mathrm{Hg}$ pada sayuran di desa Kopeng Kabupaten Semarang

Indira Casheila Anindityo ${ }^{1}$, Nur Endah Wahyuningsih ${ }^{2}$, Yusniar Hanani Darundiati ${ }^{3}$

Analisis Pelaksanaan Program Indonesia Sehat Dengan Pendekatan Keluarga (Pispk) Dalam Capaian Indeks Keluarga

Sehat Di Kabupaten Brebes Tahun 2020 Studi Pada Puskesmas Kluwut Kabupaten Brebes

Rizky Aprilianti Lestari ${ }^{1}$ dr. Antono Suryoputro ${ }^{1}$ Dr. dr. Apoina Kartini. M. Kes ${ }^{1}$

Disiplin Keselamatan dan Kesehatan Kerja melalui pemakaian alat pelindung diri di laboratorium kimia PT Sucofindo

Jakarta

Susan Endah Kartikasari ${ }^{1}$, Tatan Sukwika ${ }^{2}$

Perbedaan Pengetahuan Anemia dan Tablet Tambah Darah (TTD) Sebelum dan Sesudah Pendidikan Kesehatan Melalui

Media Video dan Aplikasi Quizlet

Devita Sari ${ }^{1}$, Gisely Vionalita ${ }^{2}$

Tingkat Pengetahuan Dan Perilaku Mahasiswi Mengenai Legalitas Dan Keamanan Kosmetik

Hani Sri Fitriani, Rizki Siti Nurfitria

Evaluasi Manajemen Dokumen Rekam Medis Di Filing Aktif Rumah Sakit Swasta Kabupaten Semarang

Bobby Anggara Laksana Putra ${ }^{1}$, Retno Astuti Setjaningsih ${ }^{2}$

Tingkat Pengetahuan Gizi Seimbang dan Profil Kesehatan Sopir Bus Antar Kota

Vilda Ana Veria Setyawati ${ }^{1}$, Bayu Yoni Setyo Nugroho ${ }^{1}$

Pengaruh Pengetahuan Dan Motivasi Kerja Terhadap Penerapan Early Warning Score System Di Rsup H Adam Malik Ita Riahna Pinem ${ }^{1}$, Zulfendri', Siti Saidah Nasution ${ }^{3}$

Analisis Penelusuran Masker Sebagai Protokol Kesehatan Saat Pandemi Covid-19 Di Indonesia: Studi Google Trends Ully Febra Kusuma ${ }^{1}$, Nurunnisa Arsyad ${ }^{2}$, Melissa Shalimar Lavinia ${ }^{3}$, Selvia Rahayu ${ }^{4}$, M. Khairul Kahfi , Rizma Adllia Syakurah ${ }^{6}$ Perilaku Hidup Bersih Dan Sehat (Phbs) Dengan Kejadian Sakit Pada Siswa Sekolah Dasar Di Kabupaten Banyumas Windri Lesmana Rubai ${ }^{1}$, Pramesthi Widya Hapsari', Katri Andirini Surijati ${ }^{3}$

Identifikasi Risiko Ganguan Muskuloskletal Pada Pekerja Percetakan Dengan Metode Nordic Body Map

Octavianus Hutapea ${ }^{1}$, Moch.Sahri', Rustam Basuki ${ }^{3}$

Literatur review: Implementasi Bauran Pemasaran 7P Terhadap Tingkat Kepuasan Pasien Di Rumah Sakit

Desi Natalia Marpaung ${ }^{1}$ Ernawaty $^{2}$ Diansanto Prayoga ${ }^{3}$ Syifa'ul Lailiyah $^{4}$

Kelengkapan Informasi Medis Untuk Mendukung Kodefikasi Penyakit Jantung Guna Mewujudkan Kualitas Data Informasi Medis Di Rumah Sakit Islam Sultan Agung Semarang

Dyah Ernawati ${ }^{1}$, Ratna Rifatul Ulya ${ }^{2}$, Arif Kurniadi ${ }^{3}$

Kajian Faktor Kendala Dokter Tidak Menggunakan Aplikasi Wifi Tb Di Kota Semarang

Arif Kurniadi', Evina Widianawati2, Dyah Ernawati ${ }^{3}$

Analisis Pelaksanaan Program Penanggulangan Tuberkulosis Paru Di Puskesmas Purwoyoso Kota Semarang

Nahari Ratu Cempaka Wilis ${ }^{1}$ Hardi Warsono ${ }^{2}$ M. Sakundarno Adi ${ }^{3}$

Hubungan Penggunaan Alat Pelindung Diri (Apd) Dengan Kadar Sgot Dan Sgpt Dalam Darah Pada Petani Padi

Iga Maliga, Rafi'ah

Faktor Risiko Kejadian Stunting Pada Balita di Wilayah Kerja Puskesmas Pandan Kabupaten Sintang

${ }^{1}$ Agustini Elisabet, ${ }^{2}$ Elvi Juliansyah

Peran Suami Dan Petugas Kesehatan Dengan Deteksi Dini Kanker Serviks

Christina Leasa, ${ }^{1}$ Mariene Wiwin Dolang

Analisis Penerapan Protokol Kesehatan terhadap Tingkat Kepatuhan Pada Pekerja informal Selama Pandemi Covid-19

MG Catur Yuantari ${ }^{1}$, Enny Rachmani ${ }^{2}$, Eti Rimawati ${ }^{1}$, Sri Handayani ${ }^{1}$, Edi Jaya Kusuma ${ }^{2}$

Peran Pengawas Minum Obat Dan Pendampingan Berobat Ulang Dengan Keberhasilan Pengobatan Tb Paru

Taswin $^{\left.1^{*}\right)}$, (zan $^{1)}$, Wahyuddin $^{1)}$, Dahmar ${ }^{1)}$

Faktor Determinan Sosial Dan Gambaran Kejadian Post Traumatic Syndrome Disorder (Ptsd) Pasca Banjir Di Dki Jakarta

Dan Bekasi Tahun 2020

Thresya Febrianti ${ }^{1}$, Nurfadhillah ${ }^{2}$, Mitha Nurhjanah ${ }^{3}$, Tiara Kautsa Aliefya ${ }^{4}$

Perbedaan Pola Makan Pada Balita Stunting Dan Tidak Stunting Di Kecamatan Teon Nila Serua (Tns) Kabupaten Maluku Tengah

Trixie Leunupun ${ }^{1}$, Ani Margawati' ${ }^{2}$ Annastasia Ediati ${ }^{3}$

Gambaran Pengelolaan Rekam Medis Rawat Inap Di Rsud Syekh Yusuf Kab. Gowa Tahun 2019

Zilfadhilah Arranury*, Surahmawati, Muhammad Rusmin, Tri Addya Karini, Dian Rezki Wijaya, Ranti Ekasari, Jihan Sulfitri

Analisis Risiko Kesehatan dalam Pemanfaatan Kemball Limbah Sludge Industri Makanan PT. X

Sri Slamet Mulyati ${ }^{1}$, Fajar Sihite ${ }^{2}$ 


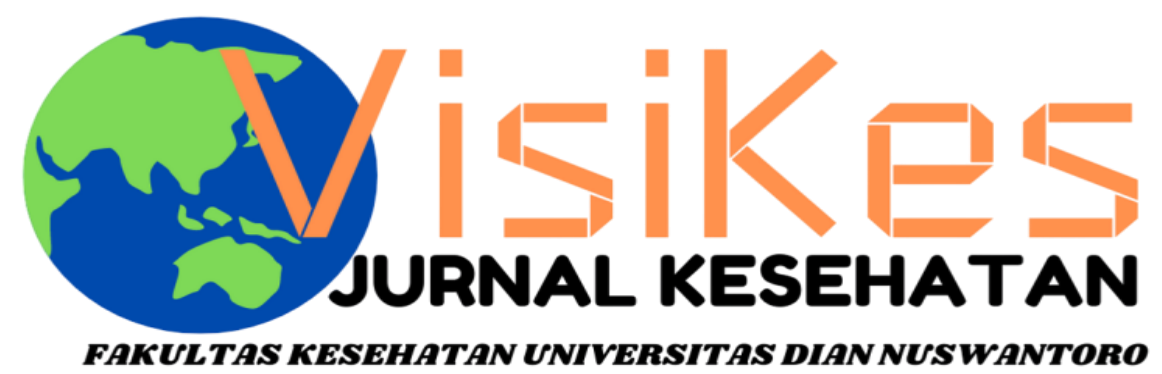

Volume 20, Nomor 1, April 2021

\section{Ketua Redaksi}

Dr. Drs. Slamet Isworo, M.Kes

\section{Penyunting}

Enny Rachmani, SKM, M.Kom, Ph.D

Fitria Wulandari, SKM, M.Kes

\section{Sekretariat}

Lice Sabata, SKM

Desain dan Layout

Puput Nur Fajri, SKM

\section{Alamat Redaksi}

Fakultas Kesehatan Universitas Dian Nuswantoro Jl. Nakula I No. 5-11 Semarang Telp/fax. (024) 3549948

email : visikes@fkes.dinus.ac.id

website $\quad$ : http://publikasi.dinus.ac.id/index.php/visikes/index

VisiKes diterbitkan mulai Maret 2002

Oleh Fakultas Kesehatan Universitas Dian Nuswantoro 


\title{
Literatur review: Implementasi Bauran Pemasaran 7P Terhadap Tingkat Kepuasan Pasien Di Rumah Sakit
}

\author{
Desi Natalia Marpaung ${ }^{1}$ Ernawaty $^{2}$ Diansanto Prayoga ${ }^{3}$ Syifa'ul Lailiyah ${ }^{4}$ \\ IImu Kesehatan Masyarakat, Kesehatan Masyarakat, Universitas Airlangga Surabaya, Indonesia \\ desi.natalia.marpaung-2017@fkm.unair.ac.id / 081359298269
}

\begin{abstract}
The marketing mix is a strategy by hospitals to maximize service delivery to clients. This study aims to analyze effect of the 7P marketing mix (product, price, place, promotion, process, people, physical building) on patient satisfaction in the hospital. The writing method of the literature review starts with selecting topics, determining keywords to finding journal references. The databases used include Google Scholar, Elsevier, Portal Garuda, Shinta. Reference searches are limited from 2016 to 2020. The keywords used are "Marketing Mix, 7p Marketing Mix, Hospital, Patient Satisfaction". This study searched list of study references that included 85 studies taken from the search. A total of 25 articles were included in the cleaning and 7 articles were included in the discussion. The selection journals is selected based on inclusion criteria. The inclusion criterion in this study is an analysis of the effect of the 7P Marketing Mix on Patient Satisfaction in the Hospital. Based on the 7 studies reviewed, one study explained that the $7 P$ marketing mix had a significant effect on patient satisfaction through statistical tests with a value of $p=0.00<\alpha=0.05$. Optimizing the 7P marketing in the hospital will have a positive impact on increasing patient satisfaction
\end{abstract}

Keywords : Hospital, Marketing Mix, Marketing Mix 7P, Patient Satisfaction

\section{PENDAHULUAN}

Rumah sakit merupakan salah satu penyedia layanan kesehatan secara paripurna dan komprehensif serta selalu berupaya memberikan layanan yang berkualitas serta memiliki daya saing untuk mencapai derajat kesehatan masyarakat yang setinggi-tingginya. Undang-Undang Republik Indonesia Nomor 44 Tahun 2009 Tentang Rumah Sakit, menjelaskan bahwa rumah sakit bertugas memberikan pelayanan terhadap kesehatan individu secara pleno yang terdiri dari promotif, preventif, kuratif dan rehabilitatif melalui pelayanan rawat inap, rawat jalan dan gawat darurat. Selain memiliki fungsi sosial, rumah sakit juga memiliki fungsi komersial dalam memelihara serta meningkatkan pelayanan operasional organisasinya. Untuk dapat menjalankan fungsi tersebut, tentu rumah sakit membutuhkan benefit atau biaya, guna mempertahankan kualitas pelayanannya. Berdasarkan permasalahan tersebut setiap rumah sakit berupaya untuk memberikan layanan dengan mengutamakan kepuasan terhadap kebutuhan dan keinginan para pengguna jasa.

Layanan kesehatan yang diberikan oleh rumah sakit harus menyesuaikan dengan karakteristik pasien yang dalam hal ini tentunya berbeda-beda, Oleh karena itu, pelayanan kesehatan ini dituntut untuk menampilkan keunggulan yang kreatif dan inovatif diantara para pesaingnya, serta rumah sakit harus menciptakan strategi khusus supaya masyarakat tertarik untuk menggunakan jasa layanan serta memberikan kepercayaan atas setiap tindakan pelayanan 
yang mereka dapatkan. Salah satu strategi yang perlu ditekankan yaitu dalam metode pemasaran. Setiap aktivitas pemasaran harus memberikan value yang unggul terhadap calon pengguna jasa. Penelitian (Marsih, Saragih et al., 2017) menyebutkan tujuan marketing yang dilakukan oleh rumah sakit adalah untuk mempublikasikan instansinya kepada masyarakat luas, menginformasikan ketersediaan peralatan kesehatan yang lengkap serta memiliki kemampuan dalam memberikan pelayanan secara maksimal kepada masyarakat luas juga kepada semua pihak terkait didalam rumah sakit, meningkatkan citra rumah sakit melalui dukungan serta penghargaan dari masyarakat, dan mengelola seluruh SDM secara optimal yang pada akhirnya bertujuan untuk meningkatkan income rumah sakit.

Hurriyati (2015), dalam penelitian (Rahmi et al, 2020) menyebutkan bahwa bauran pemasaran merupakan gabungan dari produk, harga, promosi, tempat, SDM, bukti fisik, dan proses (7P). Seluruh komponen tersebut berperan dalam mewujudkan kepuasan pasien yang berujung pada loyalitas pasien terhadap rumah sakit. Marketing mix (Bauran pemasaran)
merupakan pemasaran rumah sakit yang bertujuan untuk memaksimalkan upaya pemberian layanan kepada para pengguna jasa. Menurut (Kotler, 2000: P15), bauran pemasaran adalah kumpulan alat atau tools pemasaran oleh perusahaan untuk mencapai tujuan marketing pada kelompok sasaran. Komponen dalam bauran pemasaran terdiri dari produk (produk jasa), harga (tarif pelayanan kesehatan), tempat (lokasi pelayanan), promosi (promosi, komunikasi, pemasaran) orang (tenaga kesehatan), bukti fisik (tampilan fisik) dan proses (proses / prosedur pelayanan). Dalam menentukan strategi bauran pemasaran, rumah sakit harus menentukan prioritas pelayanan yang berkaitan dengan tujuan jangka panjang rumah sakit, Kepuasan pasien menempati prioritas tinggi dikarenakan kepuasan pasien mencerminkan efektivitas rumah sakit ketika memberi layanan kesehatan untuk para penguna jasa. Kepuasan dalam hal ini tentu memberikan pengaruh yang luas bagi rumah sakit, mulai dari tingkat kunjungan pasien semakin meningkat, tingkat loyalitas pasien meningkat, serta memberi peluang bagi rumah sakit untuk lebih diutamakan untuk dikunjungi dibanding penyedia layanan kesehatan yang lain. Oleh sebab itu, kepuasan pasien memberikan dampak terhadap peningkatan kualitas rumah sakit, serta keuntungan dalam kegiatan operasional rumah sakit.

Berdasarkan penjelasan diatas, maka tujuan penelitian adalah untuk melakukan analisis pengaruh bauran pemasaran 7P yakni Product, Price, Place, Promotion, People, Physical building, Process terhadap kepuasan pengguna jasa rumah sakit, serta melihat komponen apa saja yang memilki pengaruh signifikan terhadap peningkatan kepuasan pasien.

\section{METODE PENELITIAN}

Penelitian ini merupakan jenis penelitian dengan menggunakan metode studi kepustakaan atau literature review. Pencarian 
sumber referensi atau literatur berupa artikel ilmiah publikasi dimulai sejak 14 September 27 Oktober 2020. Referensi artikel ilmiah yang dimasukkan dalam

analisis adalah artikel yang membahas mengenai pengaruh implementasi marketing mix 7P terhadap kepuasan pasien di rumah sakit. Pengumpulan referensi melalui beberapa database online : (1) Google Scholar; (2) Elsevier; (3) Portal Garuda; (4) Shinta. Kata kunci yang digunakan dalam pencarian istilah : Marketing mix, Marketing mix 7P, Hospital, Patient Satisfaction, Tactic marketing. Referensi artikel dimasukkan jika terdapat : (1) manusia; (2) publikasi dalam bahasa inggris dan atau bahasa indonesia. Berdasarkan hasil pencarian sesuai dengan kata kunci, terdapat 85 artikel yang ditemukan, kemudian sebanyak 25 artikel dalam pembersihan dan 7 artikel ilmiah dalam pembahasan.

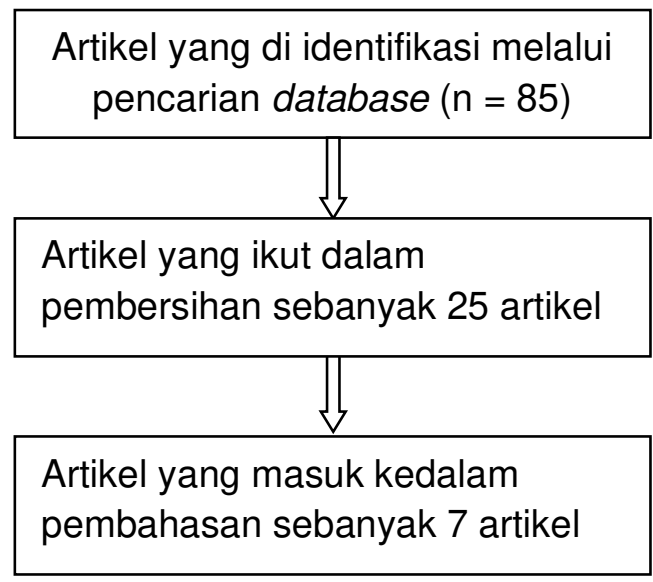

Gambar 1.1 Bagan Alur Review Artikel Yang Di Teliti

\section{HASIL}

Berdasarkan hasil penelusuran dengan menggunakan database online Google Scholar, Elsevier, Portal Garuda, Shinta dengan kata kunci yang digunakan dalam pencarian istilah : Marketing mix, Marketing mix 7P, Hospital, Patient Satisfaction, Tactic marketing, penulis menemukan sebanyak 85 artikel full text yang terbit antara 2016 - 2020, kemudian dilakukan asasemen kelayakan melalui pembersihan didapatkan 25 artikel dan sebanyak 7 artikel dalam pembahasan. Dari 7 artikel yang di review, penulis menyimpulkan sebagian besar desain penelitian artikel adalah penelitian kuantitaif dengan menggunakan pendekatan crosssectional. Hasil analisis dari semua artikel yang di review ditemukan bahwa bauran pemasaran 7P berpengaruh secara signifikan terhadap peningkatan kepuasan pasien di rumah sakit. 


\begin{tabular}{|c|c|c|c|c|c|c|}
\hline No & Author \& title & Aim & $\begin{array}{l}\text { Study } \\
\text { Design }\end{array}$ & Partcipants & Methods & Main Result \\
\hline 1 & $\begin{array}{l}\text { Tety Yuliantine } \\
\text { et al., 2018 } \\
\text { "Analysis of } \\
\text { Marketing Mix } \\
\text { Characteristics } \\
\text { of Marketing } \\
\text { Factor 7P } \\
\text { (Product, Price, } \\
\text { Place, } \\
\text { Promotion, } \\
\text { People, } \\
\text { Process, } \\
\text { Physical } \\
\text { Building) to } \\
\text { Patient } \\
\text { Satisfaction of } \\
\text { Inpatient } \\
\text { Patient Hospital } \\
\text { Muhammadiyah } \\
\text { Ahmad Dahlan } \\
\text { Kediri City" }\end{array}$ & $\begin{array}{l}\text { Tujuan } \\
\text { penelitian } \\
\text { adalah untuk } \\
\text { menganalisis } \\
\text { pengaruh } \\
\text { bauran } \\
\text { pemasaran 7P } \\
\text { terhadap } \\
\text { kepuasan } \\
\text { pasien rawat } \\
\text { inap di rumah } \\
\text { sakit } \\
\text { Muhmmadiyah } \\
\text { Ahmad Dahlan, } \\
\text { kota Kediri }\end{array}$ & $\begin{array}{l}\text { Jenis } \\
\text { penelitian } \\
\text { kuantitatif } \\
\text { dengan } \\
\text { menggunakan } \\
\text { observasional } \\
\text { analitik } \\
\text { dengan } \\
\text { pendekatan } \\
\text { cross- } \\
\text { sectional }\end{array}$ & $\begin{array}{l}\text { Total } \\
\text { keseluruhan } \\
\text { populasi } \\
\text { sebanyak } \\
600 \\
\text { Sampel } \\
\text { penelitian } \\
\text { terdiri dari } \\
240 \\
\text { responden }\end{array}$ & $\begin{array}{l}\text { Pengumpulan } \\
\text { data dengan } \\
\text { menggunakan } \\
\text { kuesioner, } \\
\text { serta uji } \\
\text { regresi linear } \\
\text { dengan } \\
\text { alpha=0,05 }\end{array}$ & 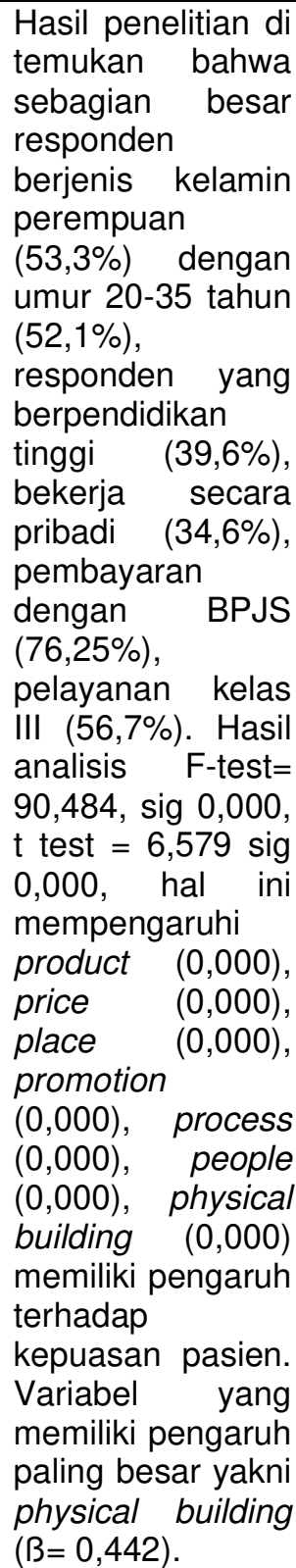 \\
\hline 2 & $\begin{array}{l}\text { Lu 'luatul Fuad } \\
\text { et al., } 2019 \\
\text { "Multilevel } \\
\text { Analysis on the } \\
\text { Effect of } \\
\text { Marketing Mix } \\
\text { Strategy } \\
\text { toward Patient } \\
\text { Satisfaction in } \\
\text { Magelang, } \\
\text { Central Java" }\end{array}$ & $\begin{array}{l}\text { Penelitian } \\
\text { bertujuan untuk } \\
\text { menggambarkan } \\
\text { pengaruh } \\
\text { bauran } \\
\text { pemasaran } \\
\text { terhadap } \\
\text { kepuasan } \\
\text { pasien di rumah } \\
\text { sakit Magelang, } \\
\text { Jawa Tengah }\end{array}$ & $\begin{array}{l}\text { Desain } \\
\text { penelitian } \\
\text { kuantitaif } \\
\text { dengan } \\
\text { menggunakan } \\
\text { pendekatan } \\
\text { cross- } \\
\text { sectional. }\end{array}$ & $\begin{array}{l}\text { Sampel } \\
\text { penelitan } \\
\text { sebanyak } \\
200 \\
\text { responden } \\
\text { dengan } \\
\text { teknik } \\
\text { random } \\
\text { sampling }\end{array}$ & $\begin{array}{l}\text { Data } \\
\text { dikumpulkan } \\
\text { melalui } \\
\text { kuesioner dan } \\
\text { dianalisis } \\
\text { dengan } \\
\text { regresi } \\
\text { logistik } \\
\text { multilevel. }\end{array}$ & $\begin{array}{l}\text { Kepuasan pasien } \\
\text { meningkat melalui } \\
\text { komponen } \\
\text { Bauran } \\
\text { pemasaran yang } \\
\text { terdiri dari produk } \\
p<0.001 \text {, harga } p \\
=0,054 \text {, tempat } p \\
=0.016 \text {, promosi } \\
p=\quad 0,004 \text {, } \\
\text { penampilan fisik } p \\
=\quad 0.015 \quad \text { dan } \\
\text { proses } p=0,039\end{array}$ \\
\hline
\end{tabular}

Tabel 1.1 Tabel Review Artikel (lanjutan) 


\begin{tabular}{|c|c|c|c|c|c|c|}
\hline No & Author \& title & Aim & $\begin{array}{l}\text { Study } \\
\text { Design }\end{array}$ & Partcipants & Methods & Main Result \\
\hline 3 & $\begin{array}{l}\text { MICHAEL } \\
\text { PEONI et al., } \\
2018 \\
\text { "Bauran } \\
\text { Pemasaran } \\
\text { Jasa Terhadap } \\
\text { Kepuasan } \\
\text { Pasien Rawat } \\
\text { Jalan } \\
\text { Rehabilitasi } \\
\text { Medik } \\
\text { Fisioterapi } \\
\text { Rumah Sakit } \\
\text { Undata Palu" }\end{array}$ & $\begin{array}{l}\text { Tujuan } \\
\text { penelitian untuk } \\
\text { mengetahui } \\
\text { pengaruh } \\
\text { bauran } \\
\text { pemasaran } \\
\text { jasa terhadap } \\
\text { kepuasan } \\
\text { pasien rawat } \\
\text { jalan } \\
\text { rehabilitasi } \\
\text { medik } \\
\text { fisioterapi } \\
\text { rumah sakit } \\
\text { Undata Palu. }\end{array}$ & $\begin{array}{l}\text { Jenis } \\
\text { penelitian } \\
\text { kuantitatif, } \\
\text { dengan } \\
\text { deskriptif } \\
\text { kausal }\end{array}$ & $\begin{array}{l}98 \text { responden } \\
\text { dengan } \\
\text { menggunakan } \\
\text { teknik } \\
\text { purposive } \\
\text { sampling. }\end{array}$ & $\begin{array}{l}\text { Metode } \\
\text { analisis data } \\
\text { yang } \\
\text { digunakan } \\
\text { dalam } \\
\text { penelitian ini } \\
\text { adalah } \\
\text { metode } \\
\text { analisis } \\
\text { regresi linear } \\
\text { berganda. }\end{array}$ & $\begin{array}{l}\text { Hasil penelitian ini } \\
\text { menunjukkan } \\
\text { bahwa faktor } \\
\text { dalam bauran } \\
\text { pemasaran jasa } \\
\text { yang terdiri dari } \\
\text { produk, harga, } \\
\text { tempat, promosi, } \\
\text { orang, bukti fisik } \\
\text { dan proses } \\
\text { berpengaruh } \\
\text { signifikan terhadap } \\
\text { kepuasan pasien } \\
\text { rawat jalan } \\
\text { rehabilitasi medik } \\
\text { rumah sakit } \\
\text { Undata Palu }\end{array}$ \\
\hline 4 & $\begin{array}{l}\text { Masri Saragih } \\
\text { et al., } 2017 \\
\text { "Faktor-Faktor } \\
\text { Bauran } \\
\text { Pemasaran } \\
\text { Yang } \\
\text { Berhubungan } \\
\text { Dengan } \\
\text { Kepuasan } \\
\text { Pasien } \\
\text { Marketing Mix } \\
\text { Factors That } \\
\text { Related With } \\
\text { Patient } \\
\text { Satisfaction" }\end{array}$ & $\begin{array}{l}\text { Tujuan } \\
\text { penelitian untuk } \\
\text { mengetahui } \\
\text { faktor bauran } \\
\text { pemasaran } \\
\text { yang memiliki } \\
\text { hubungan } \\
\text { dengan } \\
\text { kepuasan } \\
\text { pasien di } \\
\text { Instalasi Rawat } \\
\text { Jalan Rumah } \\
\text { Sakit Umum } \\
\text { Sari Mutiara } \\
\text { Medan }\end{array}$ & $\begin{array}{l}\text { Jenis } \\
\text { penelitian } \\
\text { kuantitif } \\
\text { dengan } \\
\text { metode } \\
\text { rancangan } \\
\text { cross } \\
\text { sectional }\end{array}$ & $\begin{array}{l}\text { jumlah } \\
\text { populasi } \\
6.051 \text { dan } \\
\text { sampel } \\
\text { sebanyak } 100 \\
\text { orang }\end{array}$ & $\begin{array}{l}\text { Teknik } \\
\text { sampling } \\
\text { menggunakan } \\
\text { metode } \\
\text { accidental } \\
\text { sampling dan } \\
\text { pengumpulan } \\
\text { data melalui } \\
\text { kuesioner }\end{array}$ & $\begin{array}{l}\text { Hasil penelitian } \\
\text { menunjukkan } \\
\text { terdapat hubungan } \\
\text { antara variabel } \\
\text { Produk dengan } \\
\text { kepuasan pasien } \\
p \text {-value }<\alpha \\
(0,000<0.005), \\
\text { terdapat hubungan } \\
\text { variabel lokasi } \\
\text { dengan kepuasan } \\
\text { pasien dengan } \\
\text { nilai } p \text {-value }<\alpha \\
(0,001<0.005), \\
\text { terdapat hubungan } \\
\text { variabel promosi } \\
\text { dengan kepuasan } \\
\text { pasien dengan } \\
\text { nilai } p \text {-value }<\alpha \\
(0,013<0.005), \\
\text { terdapat hubungan } \\
\text { variabel petugas } \\
\text { rumah sakit } \\
\text { dengan kepuasan } \\
\text { pasien dengan } \\
\text { nilai } p \text {-value }<\alpha \\
(p=0,000: p<0.005 \text { ). }\end{array}$ \\
\hline
\end{tabular}


Tabel 1.1 Tabel Review Artikel (lanjutan)

\begin{tabular}{|c|c|c|c|c|c|c|}
\hline No & Author \& title & Aim & $\begin{array}{c}\text { Study } \\
\text { Design }\end{array}$ & Partcipants & Methods & Main Result \\
\hline 5 & $\begin{array}{l}\text { Novi Henriyati } \\
\text { Rahmi et al., } \\
2019 \\
\text { "Pengaruh } \\
\text { Bauran } \\
\text { Pemasaran } \\
\text { Jasa Dan } \\
\text { Kualitas } \\
\text { Pelayanan } \\
\text { Kesehatan } \\
\text { Puskesmas } \\
\text { Bojong } \\
\text { Nangka } \\
\text { Terhadap } \\
\text { Kepuasan } \\
\text { Pasien Bpjs" }\end{array}$ & $\begin{array}{l}\text { Tujuan dari } \\
\text { penelitian untuk } \\
\text { mengetahui } \\
\text { apakah } \\
\text { terdapat } \\
\text { pengaruh } \\
\text { bauran } \\
\text { pemasaran jasa } \\
\text { (7P) terhadap } \\
\text { kepuasan } \\
\text { pasien BPJS }\end{array}$ & $\begin{array}{l}\text { Penelitian } \\
\text { analisis } \\
\text { deskriptif } \\
\text { metode } \\
\text { potong lintang } \\
\text { atau cross } \\
\text { sectional. }\end{array}$ & $\begin{array}{l}\text { Sampel } \\
\text { penelitian } \\
\text { berjumlah } \\
100 \text { orang }\end{array}$ & $\begin{array}{l}\text { Metode } \\
\text { pengumpulan } \\
\text { data berupa } \\
\text { kuesioner } \\
\text { dan } \\
\text { observasi. } \\
\text { Analisis data } \\
\text { penelitian } \\
\text { yaitu dengan } \\
\text { uji Regresi } \\
\text { Linier } \\
\text { Berganda } \\
\text { dengan hasil } \\
\text { Y1 } 1,515+ \\
0,064 X 1+ \\
0,073 X 2 \text {. }\end{array}$ & $\begin{array}{l}\text { Bauran pemasaran } \\
(7 P) \text { dan kualitas } \\
\text { pelayanan } \\
\text { kesehatan } \\
\text { memberikan } \\
\text { berpengaruh } \\
\text { secara bersamaan } \\
\text { terhadap kepuasan } \\
\text { pasien BPJS. }\end{array}$ \\
\hline 6 & $\begin{array}{l}\text { Ridha Rianti } \\
\text { Mahyardiani et } \\
\text { al., } 2020 \\
\text { "Satisfaction } \\
\text { And Loyalty } \\
\text { Test On Rsia } \\
\text { Budi } \\
\text { Kemuliaan } \\
\text { Patients Using } \\
\text { Marketing Mix" }\end{array}$ & $\begin{array}{l}\text { Tujuan dari } \\
\text { penelitian } \\
\text { adalah: } \\
\text { 1) } \\
\text { Menganalisis } \\
\text { pengaruh } \\
\text { bauran } \\
\text { pemasaran } \\
\text { (7P) terhadap } \\
\text { kepuasan } \\
\text { pasien di RSIA } \\
\text { Budi } \\
\text { Kemuliaan; 2) } \\
\text { Menganalisis } \\
\text { pengaruh } \\
\text { kepuasan } \\
\text { terhadap } \\
\text { loyalitas pasien } \\
\text { lama di RSIA } \\
\text { Budi } \\
\text { Kemuliaan; 3) } \\
\text { Merumuskan } \\
\text { implikasi } \\
\text { manajerial yang } \\
\text { dapat } \\
\text { meningkatkan } \\
\text { kepuasan dan } \\
\text { loyalitas } \\
\text { konsumen } \\
\text { terhadap RSIA } \\
\text { Budi Kemuliaan }\end{array}$ & $\begin{array}{l}\text { Penelitian } \\
\text { menggunakan } \\
\text { pendekatan } \\
\text { kuantitatif, } \\
\text { metode survei } \\
\text { dengan } \\
\text { pengambilan } \\
\text { data } \\
\text { menggunakan } \\
\text { kuesioner } \\
\text { berbentuk } \\
\text { skala likert }\end{array}$ & $\begin{array}{l}\text { Jumlah } \\
\text { sampel } \\
\text { sebanyak } \\
225 \\
\text { responden } \\
\text { dengan } \\
\text { teknik } \\
\text { convenience } \\
\text { sampling } \\
\text { sebesar }\end{array}$ & $\begin{array}{l}\text { Analisis data } \\
\text { yang } \\
\text { digunakan } \\
\text { adalah SEM }\end{array}$ & $\begin{array}{l}\text { Hasil penelitian } \\
\text { menunjukkan } \\
\text { bahwa variabel } \\
\text { bauran pemasaran } \\
\text { yang memengaruhi } \\
\text { kepuasan dan } \\
\text { loyalitas pasien } \\
\text { adalah harga } \\
\text { (price), } \\
\text { orang/pelaku } \\
\text { (people), proses } \\
\text { (process), dan } \\
\text { bukti fisik } \\
\text { (physicalevidence). }\end{array}$ \\
\hline
\end{tabular}


Tabel 1.1 Tabel Review Artikel (lanjutan)

\begin{tabular}{|c|c|c|c|c|c|c|}
\hline No & Author \& title & Aim & $\begin{array}{l}\text { Study } \\
\text { Design }\end{array}$ & Partcipants & Methods & Main Result \\
\hline 7 & $\begin{array}{l}\text { Dyah Sawitri et } \\
\text { al., } 2016 \\
\text { "Pengaruh } \\
\text { Marketing Mix } \\
\text { Terhadap } \\
\text { Loyalitas } \\
\text { Konsumen } \\
\text { DenganVariabel } \\
\text { Intervening } \\
\text { Kepuasan Pada } \\
\text { Rumah Sakit } \\
\text { Jiwa } \\
\text { Dr.Radjiman } \\
\text { Wediodiningrat" }\end{array}$ & $\begin{array}{l}\text { Tujuan } \\
\text { penelitian } \\
\text { adalah untuk } \\
\text { menganalisis } \\
\text { signifikasinsi } \\
\text { dan efek positif } \\
\text { bauran } \\
\text { pemasaran } \\
\text { terhadap } \\
\text { kepuasan } \\
\text { pasien }\end{array}$ & $\begin{array}{l}\text { Penelitian } \\
\text { eksplanatori } \\
\text { dengan } \\
\text { menggunakan } \\
\text { survei } \\
\text { metodologi. }\end{array}$ & $\begin{array}{l}100 \text { keluarga } \\
\text { pasien } \\
\text { skizofrenia }\end{array}$ & $\begin{array}{l}\text { Analisis } \\
\text { statistik yang } \\
\text { digunakan } \\
\text { adalah path } \\
\text { analisis dan } \\
\text { perhitungan } \\
\text { asumsi nilai } \\
\text { parametrik } \\
\text { mengunakan } \\
\text { SPSS } 20.0\end{array}$ & $\begin{array}{l}\text { Bauran } \\
\text { pemasaran } \\
\text { berpengaruh } \\
\text { positif dan } \\
\text { signifikan } \\
\text { terhadap tingkat } \\
\text { kepuasan } \\
\text { konsumen di klinik } \\
\text { psikiatri rawat } \\
\text { jalan RSJ } \\
\text { Dr,Radjiman. } \\
\text { Wediodiningrat, } \\
\text { Lawang, Mental } \\
\text { Hospital }\end{array}$ \\
\hline
\end{tabular}

\section{PEMBAHASAN}

Bauran pemasaran merupakan sebuah upaya atau taktik pemasaran yang digunakan agar tercapai tujuan sebuah organisasi. Komponen bauran pemasaran 7P terdiri dari product, price, place, promotion, process, people, physical building. Sebagai organisasi penyedia jasa, rumah sakit harus mampu menyusun strategi bauran pemasaran dalam pemberian layanan untuk mencapai target yakni memberikan kepuasan terhadap pasien serta mendapatkan loyalitas yang tinggi dari pasien.

\section{Product}

Product merupakan sesuatu hal berupa barang atau jasa yang di produksi oleh sebuah organisasi. Produk yang dihasilkan rumah sakit berupa jasa layanan kesehatan yang diberikan kepada pasien. Penelitian Yuliantine, Indasah and Siyoto, (2018), menjelaskan bahwa jasa adalah segala sesuatu yang dipromosikan oleh organisasi atau penyedia layanan agar masyarakat tertarik untuk memperhatikan, mencari, membeli dan menggunakan jasa tersebut untuk memenuhi kebutuhan serta keinginannya. Produk terdiri dari objek fisik, layanan, orang, tempat, organisasi, dan gagasan. Dalam rumah sakit produk yang dihasilkan berupa jasa pelayanan kesehatan yang dibutuhkan oleh pasien.

\section{Price}

Price merupakan salah satu faktor penentu jenis layanan yang akan disediakan dan akan diberikan kepada pasien. Faktor selanjutnya yang mempengaruhi Kepuasan adalah harga, apabila harga dari setiap pelayanan yang diberikan terjangkau oleh konsumen, akan berdampak pada peningkatan kepuasan pasien terhadap penyedia layanan tersebut, sebaliknya semakin tinggi harga atau 
semakin mahal harga dari setiap pelayanan dapat menjadi salah satu faktor yang menyebabkan menurunnya tingkat kepuasan pasien. Penelitian Lu'luatul et al, (2019) menjelaskan bahwa harga adalah salah satu faktor yang berpengaruh terhadap peningkatan kepuasan pasien, oleh sebab itu produsen harus memperhatikan faktor harga dalam sebuah produk yang diproduksi sebelum dipromosikan kepada konsumen.

\section{Place}

Place atau lokasi merupakan faktor utama sebelum produsen memulai penjualan atau pemberian layanan kepada konsumen, rumah sakit sebagai penyedia layanan kesehatan harus merencanakan lokasi yang strategis serta mudah di akses oleh masyarakat agar masyarakat dapat berkunjung ke rumah sakit untuk mendapakan layanan kesehatan. Tempat atau wilayah yang strategis serta mudah dijangkau oleh masyarakat juga merupakan salah satu faktor penentu tingkat kepuasan pasien, semakin mudah nya akses ke rumah sakit akan memerikan pengaruh terhadap meningkatkatnya kepuasan pasien. Penelitian PEONI and PARUBAK, (2018) menjelaskan tempat atau lokasi berpengaruh terhadap peningkatan kepuasan pasien rawat jalan dikarenakan letak rumah sakit yang strategis serta mudah diakses oleh masyarakat.

\section{Promotion}

Promotion adalah bagian dari komponen pemasaran yang bertujuan untuk meningkatan penjualan produk atau jasa atau layanan promosi yang berisi informasi untuk pelanggan potensial dan yang sudah ada. Dalam penelitian (Marsih, Saragih et al., 2017) menjelaskan bahwa komponen promosi berpengaruh terhadap kepuasan pasien.

\section{People}

(Mahyardiani, Hartoyo and Krisnatuti, 2020) menjelaskan, people adalah semua sumber daya manusia yang terlibat ketika memberikan pelayanan melalui barang atau jasa kepada konsumen. SDM rumah sakit terdiri dari dokter, perawat, karyawan dan semua aspek di rumah sakit. Semua tindakan dari SDM akan berpengaruh terhadap kepuasan para pengguna jasa layanan kesehatan, mulai dari cara berpakaian hingga cara beromunikasi kepada pasien dan juga keluarga pasien. Booms dan Bitner menjelaskan bahwa pemasaran layanan telah lama menekankan pentingnya staf dan terutama staf kontak pelanggan sebagai komponen penting dalam memberikan layanan berkualitas tinggi dan berkontribusi pada kepuasan pelanggan secara keseluruhan.

\section{Process}


Proses merupakan saat dimana produsen memberikan produk kepada konsumen. Penelitian (Sawitri, 2016) menyebutkan dalam rumah sakit proses pelayanan meliputi ketepatan waktu pada saat memberikan pelayanan, lama waktu tunggu untuk mendapat layanan dari dokter, lama waktu tunggu untuk mendapatkan obat. Proses tersebut memberikan pengaruh terhadap peningkatan loyalitas pasien yang pada akhirnya berdampak pada peningkatan kepuasan pasien terhadap pelayanan yang diberikan. Penelitian (Lu'luatul et al, Tamtomo and Sulaeman, 2019) menyebutkan proses adalah faktor utama dalam memberikan layanan, karena konsumen akan memandang sistem penyampaian layanan sebagian dari layanan. Jika proses dilakukan dengan baik maka pasie akan memiliki tingkat kepuaasan yang tinggi dan juga sebaliknya.

\section{Physical building}

Bukti fisik adalah anggapan atau persepsi pasien terhadap segala hal yang secara langsung dapat dilihat dan dirasakan, (PEONI and PARUBAK, 2018). Beberapa indikator dalam faktor bukti fisik adalah sarana parkir, kebersihan ruang perawatan, serta keseragaman tenaga kesehatan saat bertugas. Menurut zeithmal dan Berry dalam Tjiptono,2014 dalam penelitian (Yuliantine, Indasah and Siyoto, 2018) menyebutkan aspek kepuasan pasien meliputi estetika berupa pelayanan yang berkaitan dengan tata ruang serta keindahan ruangan. Bukti fisik adalah merupakan sebuah ruang tempat pelayanan untuk dapat berinteraksi secara langsung dengan konsumen.

\section{SIMPULAN DAN SARAN}

Bauran pemasaran (Product, Price, Promotion, People, Place, Process, Physical building) 7P berperan penting dalam pengambilan keputusan serta kebijakan bagi rumah sakit. Bauran pemasaran terdiri dari beberapa komponen. Setiap Komponen dalam bauran pemasaran memberikan pengaruh yang berbeda terhadap tingkat kepuasan yang dirasakan oleh pasien. Komponen yang memberikan pengaruh secara signifikan terhadap kepuasan pasien akan berdampak pula pada loyalitas pasien terhadap rumah sakit. Oleh karena itu, sistem manajemen rumah sakit khususnya bidang pemasaran di tuntut untuk mampu mengoptimalkan dan mengembangkan jenis pemasaran yang dapat meningkatkan minat masyarakat sehingga target keuntungan rumah sakit dapat tercapai, begitu pula dengan komponen pemasaran yang tidak memberikan pengaruh signifikan, rumah sakit diharapkan dapat membentuk strategi yang lebih baik agar komponen tersebut dapat memberikan pengaruh dalam peningkatan kepuasan pasien. Sebuah rumah sakit ketika sudah memahami kekurangan dalam mengoptimalkan aktivitas pemasaran, maka seluruh pihak dalam rumah sakit dapat bekerja sama dan saling berkoordinasi untuk 
menentukan prioritas pemasaran yang sesuai dengan kebutuhan dan target pasar.

Berdasarkan hasil analisis oleh peneliti, maka diharapkan pihak manajemen rumah sakit agar selalu mengoptimalkan serta mengembangkan strategi marketing dalam rumah sakit agar masyarakat atau pengguna jasa memberikan tingkat kepuasan yang tinggi serta memiliki loyalitas yang tinggi terhadap rumah sakit. Untuk penelitian selanjutnya, disarankan memperluas materi mengenai marketing Mix dalam rumah sakit, tidak terbatas pembahasan mengenai dampak eksternal rumah sakit tetapi juga terhadap internal rumah sakit.

\section{DAFTAR PUSTAKA}

1. Lu'luatul et al, Tamtomo, D. and Sulaeman, E. S. (2019) 'Multilevel Analysis on the Effect of Marketing Mix Strategy toward Patient Satisfaction in Magelang, Central Java', Journal of Health Policy and Management, 4(1), pp. 39-46. doi:

10.26911/thejhpm.2019.04.01.05.

2. Mahyardiani, R. R., Hartoyo, H. and Krisnatuti, D. (2020) 'Menguji Kepuasan Dan Loyalitas Pasien Rsia Budi Kemuliaan Menggunakan Bauran Pemasaran', Jurnal Aplikasi Bisnis dan Manajemen, 6(1), pp. 1-13. doi: 10.17358/jabm.6.1.1.

3. Marsih, Saragih et al., 2017 (2017) 'Faktor-Faktor Bauran Pemasaran Yang Berhubungan Dengan Kepuasan Pasien', Idea Nursing Journal, 8(2), pp. 1-6.

4. PEONI, M. and PARUBAK, E. R. B. (2018) 'Bauran pemasaran jasa terhadap kepuasan pasien rawat jalan rehabilitasi medik fisioterapi rumah sakit undata palu', 4(2), pp. 173-184.

5. Rahmi et al, 2020 (2020) 'The influence of marketing mix and service quality of Puskesmas Bojong Nangka against BPJS patient satisfaction', Farmasains: Jurnal Farmasi dan IImu Kesehatan, 4(2), pp. 41-50.

doi: 10.22219/farmasains.v4i2.8840.

6. Bahadori $M$, Teymourzadeh $E$, Ravangard R, Nasiri A, Raadabadi M, Alimoham-madzadeh K (2016). Factors contribu-ting towards patient's choice of a hospital clinic from the patients' and managers' perspective. Electronic Physician, 8(5): 2378-2387. doi: 10.19082/2378.

7. Hakim FR, Nuryadi, Sandra C. 2015. Hubungan bauran pemasaran dan faktor psikologis denganproses pengambilan keputusan pasien dalampemanfaatan rawat jalan. E-Jurnal Pustaka Kesehatan 3(3):484-491.

8. Sawitri, D. et al (2016) 'PENGARUH MARKETING MIX TERHADAP LOYALITAS KONSUMEN DENGAN VARIABEL INTERVENING KEPUASAN PADA RUMAH SAKIT JIWA Dr. RADJIMAN WEDIODININGRAT', 4(June), pp. 67-86.

9. Yuliantine, T., Indasah, I. and Siyoto, S. (2018) 'Analysis of Marketing Mix Characteristics of Marketing Factor 7P (Product, Price, Place, Promotion, People, Process, Physical Building) to Patient Satisfaction of Inpatient Patient 
Hospital Muhammadiyah Ahmad Dahlan

Kediri City', Journal for Quality in Public

Health, 1(2), pp. 50-57. doi: 10.30994/jqph.v1i2.17.

10. Nugraheni,G., Putri,L.R., Setiawan,C.D., Wijaya,I.N., 2016, Kepuasan Pasien BPJS Kesehatan Terhadap Kualitas
Pelayanan Kefarmasian di Pusat Kesehatan Masyarakat (Analisis Menggunakan Servqual Model Dan Customer Window Quadrant), Prosiding Rakernas dan Pertemuan IImiah Tahunan Ikatan Apoteker Indonesia: hal. 198, 204. 